\title{
Eating disorders in young males: moving beyond stereotype and stigma
}

\author{
Chloe Shu', Karina Limburg ${ }^{1}$, Hunna Watson ${ }^{2}$, Chris Harris $^{3}$, Julie McCormack', Kimberley Hoiles ${ }^{1 *}$, David Forbes ${ }^{4}$ \\ From 2014 ANZAED Conference: Driven Bodies Driven Brains \\ Fremantle, Australia. 22-23 August 2014
}

\section{Objective}

To provide knowledge about the clinical presentation of eating disorders in young males ( $<18$ years).

\section{Method}

The sample comprised young males with eating disorders $(n=53)$ and females with eating disorders $(n=704)$. The data source was the Helping to Outline Paediatric Eating Disorders (HOPE) Project registry $(\mathrm{N} \sim 1000)$, a prospective and ongoing registry study comprising consecutive paediatric tertiary eating disorder referrals.

\section{Results}

Young males with eating disorders more commonly presented with unspecified eating disorders (40\%). In comparison to young females with eating disorders young males were less likely to report self-induced purging, endorsed lower weight concern, and presented with an earlier age of onset. Young males and females presented with a similar duration of untreated illness.

\section{Discussion}

Young males with eating disorders are an understudied group who are systematically different from young females with eating disorders. Diagnostic classification, assessment instruments, conceptualisation and treatment methods need to be refined to improve application to young males.

This abstract was presented in the Service Initiatives: Child and Adolescent stream of the 2014 ANZAED Conference.

\section{Authors' details}

'Eating Disorders Program, Specialised Child and Adolescent Mental Health Service, Child and Adolescent Health Service, Department of Health in Western Australia, Perth, Australia. ${ }^{2}$ UNC Center of Excellence for Eating Disorders, University of North Carolina, Chapel Hill, North Carolina, USA. ${ }^{3}$ YouthFocus, Perth, Australia. ${ }^{4}$ School of Paediatrics and Child Health, Faculty of Medicine, Dentistry and Health Sciences, The University of Western Australia, Perth, Australia.

Published: 24 November 2014

doi:10.1186/2050-2974-2-S1-O54

Cite this article as: Shu et al:: Eating disorders in young males: moving beyond stereotype and stigma. Journal of Eating Disorders 2014 2(Suppl 1):054

* Correspondence: Kimberley.Hoiles@health.wa.gov.au

${ }^{1}$ Eating Disorders Program, Specialised Child and Adolescent Mental Health Service, Child and Adolescent Health Service, Department of Health in Western Australia, Perth, Australia

Full list of author information is available at the end of the article

Submit your next manuscript to BioMed Central and take full advantage of:

- Convenient online submission

- Thorough peer review

- No space constraints or color figure charges

- Immediate publication on acceptance

- Inclusion in PubMed, CAS, Scopus and Google Scholar

- Research which is freely available for redistribution
() Biomed Central 